\title{
Insights from the STICH trial: Change in left ventricular size after coronary artery bypass grafting with and without surgical ventricular reconstruction
}

\author{
Robert E. Michler, MD, ${ }^{\mathrm{a}}$ Jean L. Rouleau, MD, ${ }^{\mathrm{b}}$ Hussein R. Al-Khalidi, PhD, ${ }^{\mathrm{c}}$ Robert O. Bonow, MD, ${ }^{\mathrm{d}}$ \\ Patricia A. Pellikka, MD, ${ }^{\mathrm{e}}$ Gerald M. Pohost, MD ${ }^{\mathrm{f}, \mathrm{g}}$ Thomas A. Holly, MD, ${ }^{\mathrm{d}}$ Jae K. Oh, MD, ${ }^{\mathrm{e}}$ \\ Francois Dagenais, MD, ${ }^{\mathrm{h}}$ Carmelo Milano, MD,${ }^{\mathrm{c}}$ Krzysztof Wrobel, MD ${ }^{\mathrm{i}}$ Jan Pirk, MD, DSc, ${ }^{\mathrm{j}}$ \\ Imtiaz S. Ali, MD, ${ }^{\mathrm{k}}$ Robert H. Jones, MD,${ }^{\mathrm{c}}$ Eric J. Velazquez, MD ${ }^{\mathrm{c}}$ Kerry L. Lee, $\mathrm{PhD},{ }^{\mathrm{c}}$ and \\ Marisa Di Donato, MD, ${ }^{1}$ for the STICH Trial Investigators
}

Objective: The present analysis of the Surgical Treatment for Ischemic Heart Failure randomized trial data examined the left ventricular volumes at baseline and 4 months after surgery to determine whether any magnitude of postoperative reduction in end-systolic volume affected survival after coronary artery bypass grafting alone compared with bypass grafting plus surgical ventricular reconstruction.

Methods: Of the 1000 patients randomized, 555 underwent an operation and had a paired imaging assessment with the same modality at baseline and 4 months postoperatively. Of the remaining 455 patients, 424 either died before the 4-month study or did not have paired imaging tests and were excluded, and 21 were not considered because they had died before surgery or did not receive surgery.

Results: Surgical ventricular reconstruction resulted in improved survival compared with coronary artery bypass grafting alone when the postoperative end-systolic volume index was $70 \mathrm{~mL} / \mathrm{m}^{2}$ or less. However, the opposite was true for patients achieving a postoperative volume index greater than $70 \mathrm{~mL} / \mathrm{m}^{2}$. A reduction in the end-systolic volume index of $30 \%$ or more compared with baseline was an infrequent event in both treatment groups and did not produce a statistically significant survival benefit with ventricular reconstruction.

Conclusions: In patients undergoing coronary artery bypass grafting plus surgical ventricular reconstruction, a survival benefit was realized compared with bypass alone, with the achievement of a postoperative endsystolic volume index of $70 \mathrm{~mL} / \mathrm{m}^{2}$ or less. Extensive ventricular remodeling at baseline might limit the ability of ventricular reconstruction to achieve a sufficient reduction in volume and clinical benefit. ( $\mathrm{J}$ Thorac Cardiovasc Surg 2013;146:1139-45)

\section{Supplemental material is available online.}

The National Heart, Lung, and Blood Institute-sponsored Surgical Treatment for Ischemic Heart Failure (STICH) randomized trial showed that the addition of surgical ventricular reconstruction (SVR) to coronary artery bypass grafting $(\mathrm{CABG})$ provided no benefit in overall survival or survival free from cardiac hospitalization compared with $\mathrm{CABG}$ alone. ${ }^{1}$ These results have generated keen interest, controversy, and widespread discussion. ${ }^{2-4}$ This interest is, in part, because of several factors unique to the STICH

\footnotetext{
From the Montefiore Medical Center, ${ }^{\text {a }}$ Albert Einstein College of Medicine, New York, NY; Montreal Heart Institute, ${ }^{\mathrm{b}}$ Université de Montréal, Montreal, Quebec, Canada; Duke Clinical Research Institute, ${ }^{\mathrm{c}}$ Duke University Medical Center, Durham, NC; Northwestern University Feinberg School of Medicine, ${ }^{\mathrm{d}}$ Chicago, Ill; Echocardiography Core Laboratory, ${ }^{\mathrm{e}}$ Mayo Clinic, Rochester, Minn; University of Southern California Keck School of Medicine, ${ }^{\mathrm{f}}$ Los Angeles, Calif; University of Southern California Viterbi School of Engineering, ${ }^{\mathrm{g}}$ Los Angeles, Calif; Laval Hospital, ${ }^{\text {h }}$ Quebec Heart Institute, Sainte-Foy, Quebec, Canada; John Paul II Hospital, ${ }^{\mathrm{i}}$ Krakow, Poland; Institute for Clinical and Experimental Medicine, ${ }^{\mathrm{j}}$ Prague, Czech Republic; Libin CV Institute of Alberta, ${ }^{\mathrm{k}}$ Calgary, Alberta, Canada; and San Donato Hospital, ${ }^{1}$ Milan, Italy.

Funding for the STICH trial was provided by grants 5U01-HL-69015, 5U01-HL69013, and 5U01-HL-69010 from the National Heart, Lung, and Blood Institute.

Disclosures: Dr Michler received research funding from the National Institutes of Health and National Heart, Lung, and Blood Institute; Dr Rouleau received research support from the National Heart, Lung, and Blood Institute; Dr Bonow
}

received research funding from the National Heart, Lung, and Blood Institute; Dr Pellikka received National Heart, Lung, and Blood Institute funding from STICH trial paid to the Echocardiography Core Laboratory; Dr Jones received research funding from the National Heart, Lung, and Blood Institute; Dr Velazquez received research funding from the National Heart, Lung, and Blood Institute and Abbott Vascular; and Dr Lee received research funding from the National Heart, Lung, and Blood Institute. The other authors have nothing to disclose with regard to commercial support.

Received for publication May 31, 2012; revisions received Aug 28, 2012; accepted for publication Sept 12, 2012; available ahead of print Oct 29, 2012.

Address for reprints: Robert E. Michler, MD, Montefiore Medical Center, Albert

Einstein College of Medicine, 3400 Bainbridge Ave, 5th Floor, New York, NY 10467 (E-mail: rmichler@montefiore.org).

0022-5223/\$36.00

Copyright (c) 2013 by The American Association for Thoracic Surgery

http://dx.doi.org/10.1016/j.jtcvs.2012.09.007 


\section{Abbreviations and Acronyms \\ $\mathrm{CABG}=$ coronary artery bypass grafting \\ ESVI $=$ end-systolic volume index \\ $\mathrm{LV}=$ left ventricular \\ STICH $=$ Surgical Treatment for Ischemic Heart Failure \\ SVR = surgical ventricular reconstruction}

population, including the broad range of baseline left ventricular (LV) volumes, adequacy of LV volume reduction achieved with SVR, and extent and severity of baseline anterior wall asynergy. Additional controversy stems from uncertainty about whether a target level exists for the LV end-systolic volume index (ESVI) that should be achieved after SVR, and whether a target level exists for the percentage of LVESVI reduction from baseline. Whether the surgical reduction in the LVESVI achieved in STICH was sufficient remains an unanswered question. Consideration must be given to the fact that the left ventricle might be made too small or allowed to remain too large with SVR. ${ }^{5,6}$ Moreover, a baseline threshold LVESVI might exist, above which the ventricle might be too large to benefit from SVR. ${ }^{7}$

To further explore these questions and the implications of the STICH results, we evaluated the distribution of LV volumes at baseline and 4 months postoperatively and the individual reductions in LV volume with surgery to determine whether a threshold post-SVR LVESVI, or any magnitude of postoperative reduction in LVESVI, affected survival after CABG plus SVR compared with CABG alone.

\section{METHODS}

\section{Patient Population}

From September 12, 2002 to January 24, 2006, 1000 patients with coronary artery disease amenable to revascularization, an ejection fraction (EF) of $35 \%$ or less, and anterior akinesia or dyskinesia amenable to SVR were randomized to receive CABG alone $(n=499)$ or CABG plus SVR $(\mathrm{n}=501)$. Follow-up continued through December 31, 2008 and was complete for $99 \%$ of the randomized patients. The median duration of follow-up was 48 months. ${ }^{1,8}$

Of the 979 patients who underwent surgery, $86(8.8 \%)$ died before their 4-month follow-up study (Figure E1). Also, 16 and 107 patients, respectively, did not have either a baseline or 4-month postoperative imaging study suitable for end-systolic volume determination by 1 of the 3 blinded imaging core laboratories for echocardiography, radionuclide imaging, or cardiac magnetic resonance studies. ${ }^{7}$ Of the remaining 770 patients, 175 had a suboptimal baseline or follow-up imaging study (less than "fair" to "excellent" quality) and 40 did not have paired imaging studies using the same modality. The present report focused only on the 555 patients who had undergone surgery and had a paired imaging assessment at baseline and 4 months postoperatively.

\section{Imaging Studies}

All patients were required to have an echocardiogram at baseline and a repeat study at the 4-month follow-up point. Cardiac magnetic resonance and radionuclide imaging at baseline and 4 months were also recommended. Because many patients had undergone studies with more than 1 imaging modality, the "best available" value of LV volume and EF was determined for each patient according to the study quality, as previously described. ${ }^{7}$ Using this approach, 195 patients with paired cardiac magnetic resonance studies, 276 with paired echocardiography studies, and 84 with paired radionuclide imaging studies were available for the analyses.

\section{Statistical Analysis}

The baseline characteristics are summarized as the mean \pm standard deviation for continuous variables and frequencies (percentages) for categorical variables. The characteristics of the patients with paired baseline and 4-month studies were compared with those without paired studies using the 2-sample $t$ test for continuous variables and Fisher's exact test for categorical variables. Changes in the LV function parameters from baseline to 4 months were compared using the paired $t$ test. Cumulative event rates were calculated using Kaplan-Meier estimates. ${ }^{9}$ Time-to-event data were analyzed using the log-rank statistic, and the Cox proportional hazards model was used to estimate hazard ratios (HRs) and $95 \%$ confidence intervals (CIs).$^{10}$ The interaction of treatment and ESVI was also assessed using the Cox model.

Three patient groups were created corresponding to previously described clinically accepted thresholds of baseline LV volumes (group 1, LVESVI $<60 \mathrm{~mL} / \mathrm{m}^{2}$; group 2, LVESVI, $60-90 \mathrm{~mL} / \mathrm{m}^{2}$; and group 3 , LVESVI $\left.>90 \mathrm{~mL} / \mathrm{m}^{2}\right)^{5,11,12}$ The baseline clinical characteristics and the magnitude of change in LV volumes from preoperatively to postoperatively were compared among these groups. Additionally, the change in ESVI was analyzed according to the specific thresholds to assess whether a differential effect (either benefit or harm) was present for CABG plus SVR versus CABG alone, depending on the magnitude of the reduction in LVESVI.

Kaplan-Meier mortality rates in the 2 treatment arms across the range of the 4-month LVESVI were constructed by choosing a specific cohort size $(\mathrm{n}=150)$ and plotting the 4-year Kaplan-Meier estimate at the median postoperative LVESVI for that cohort. We then moved this cohort across the entire range of LVESVIs, 1 patient at a time, each time adding the next larger LVESVI value and removing the smallest value (similar to a moving average). Using this method, we obtained a "smoothed" plot of mortality for the 2 treatment arms as a function of the 4-month LVESVI. ${ }^{9}$

\section{RESULTS}

The baseline characteristics of the 555 patients with both pre- and postoperative LVESVI data were similar (except for New York Heart Association class III/IV, hypertension, and diabetes) to those of the 424 excluded patients who had undergone surgery but either died before the 4-month study or did not have paired imaging tests using the same modality (Table 1). An additional 21 patients were not included in either cohort because they had either died before receiving surgery or did not receive surgery within 1 year of randomization. The survival was not similar between the 555 patients and the 424 excluded patients, reinforcing that the 555 patients were not a random sample of the 1000 patients (Figure E2). For the 555 patients with paired studies, no difference was seen in survival between $\mathrm{CABG}$ alone and CABG plus SVR (Figure E3).

The characteristics were similar for the 555 patients with paired pre- and postoperative studies undergoing CABG plus SVR or CABG alone and for the 3 patient subgroups (Table E1). The average number of distal bypass grafts 
TABLE 1. Baseline characteristics stratified by paired pre- and postoperative imaging status

\begin{tabular}{|c|c|c|c|}
\hline Variable & $\begin{array}{c}\text { Patients with } \\
\text { paired imaging } \\
\text { tests }(n=555)\end{array}$ & $\begin{array}{c}\text { Excluded } \\
\text { patients } \\
(\mathrm{n}=\mathbf{4 2 4}) \\
\end{array}$ & $\begin{array}{c}\text { Total } \\
\text { population } \\
(\mathbf{n}=979)^{*} \\
\end{array}$ \\
\hline $\operatorname{ESVI}\left(\mathrm{mL} / \mathrm{m}^{2}\right)$ & $84 \pm 34$ & $85 \pm 36$ & $86 \pm 38$ \\
\hline $\operatorname{EDVI}\left(\mathrm{mL} / \mathrm{m}^{2}\right)$ & $115 \pm 38$ & $115 \pm 40$ & $117 \pm 41$ \\
\hline LVEF $(\%)$ & $29 \pm 9$ & $28 \pm 8$ & $28 \pm 9$ \\
\hline Age $(y)$ & $61.3 \pm 9.6$ & $61.9 \pm 9.9$ & $61.6 \pm 9.7$ \\
\hline Female gender $(\%)$ & 13.2 & 15.8 & 14.3 \\
\hline Previously documented MI (\%) & 86.0 & 88.7 & 87.1 \\
\hline Hypertension $(\%)$ & $53.7 \dagger$ & 65.3 & 58.7 \\
\hline Diabetes $(\%)$ & $31.2 \dagger$ & 38.7 & 34.4 \\
\hline Angina class III or IV (\%) & 48.7 & 50.7 & 49.5 \\
\hline NYHA class III or IV $(\%)$ & $42.9 \dagger$ & 55.4 & 48.3 \\
\hline Triple vessel disease (\%) & 64.9 & 62.5 & 63.8 \\
\hline \multicolumn{4}{|l|}{ Graft number $(\%)$} \\
\hline $1-2$ & 26.9 & 30.1 & 28.3 \\
\hline $3-5$ & 71.1 & 69.7 & 70.5 \\
\hline$\geq 6$ & 2 & 0.2 & 1.2 \\
\hline MR $3+$ or $4+(\%)$ & 18.0 & 17.2 & 17.7 \\
\hline
\end{tabular}

Data presented as mean \pm standard deviation or percentages. $E D V I$, End-diastolic volume index; $E S V I$, end-systolic volume index; $L V E F$, left ventricular ejection fraction; $M I$, myocardial infarction; $M R$, mitral regurgitation; NYHA, New York Heart Association. *Twenty-one patients did not undergo surgery within 1 year of randomization and were not included in this tabulation of baseline characteristics. $\dagger P<.05$, Fisher's exact test (comparisons between paired cohort and excluded cohort).

was similar among the groups. Of note, $3+$ or $4+$ mitral regurgitation was more prevalent as the LV volume increased across each treatment group.

\section{Group 1 (Baseline LVESVI $<60 \mathrm{~mL} / \mathrm{m}^{2}$ )}

Of the 148 patients in group 1,82 had undergone CABG alone and $66 \mathrm{CABG}$ plus SVR. Neither treatment arm in this subgroup had a significant decrease in LVESVI at 4 months postoperatively (Table 2 and Figure E4, A). At 4 months, in those who had undergone CABG plus SVR, the mean LVEF increased from 0.36 at baseline to $0.40,26 \%$ of patients had a greater than $30 \%$ reduction in LVESVI from baseline, and $41 \%$ had no reduction or an increase in LVESVI. The patients who had undergone CABG alone had a smaller change in LVEF (from 0.37 to 0.39 ), $22 \%$ had a greater than $30 \%$ reduction in LVESVI, and $51 \%$ had no change or an increase in LVESVI.

\section{Group 2 (Baseline LVESVI, $60-90 \mathrm{~mL} / \mathrm{m}^{2}$ )}

Of the 203 patients in group 2,114 had undergone CABG alone and $89 \mathrm{CABG}$ plus SVR. The patients receiving CABG plus SVR had a significant decrease in LVESVI at 4 months (mean $15 \mathrm{~mL} / \mathrm{m}^{2} ; P<.0001$ ), but those receiving CABG alone did not (Table 2 and Figure $\mathrm{E} 4, B$ ). In patients receiving CABG plus SVR, the LVEF increased from 0.30 at baseline to 0.36 at 4 months, $36 \%$ of the patients had a greater than $30 \%$ reduction in LVESVI from baseline, and $12 \%$ had no reduction or an increase in LVESVI. Patients with CABG alone had a smaller increase in LVEF (from 0.29 to 0.33 ), $18 \%$ had a greater than $30 \%$ reduction in LVESVI, and nearly one half had no change or an increase in LVESVI.

\section{Group 3 (Baseline LVESVI $>90 \mathrm{~mL} / \mathrm{m}^{2}$ )}

Of the 204 patients in group 3,100 had undergone CABG alone and 104 CABG plus SVR. The patients receiving CABG plus SVR had a significant decrease in ESVI at 4 months (mean, $32 \mathrm{~mL} / \mathrm{m}^{2} ; P<.0001$ ). The patients receiving $\mathrm{CABG}$ alone had a mean decrease in ESVI of $18 \mathrm{~mL} / \mathrm{m}^{2}(P<.0001$; Table 2 and Figure $\mathrm{E} 4, C)$. In the patients receiving $C A B G$ plus $S V R$, the $L V E F$ increased from

TABLE 2. Changes in LV volumes and systolic function relative to baseline $L V$ end-systolic volume

\begin{tabular}{|c|c|c|c|c|c|c|}
\hline \multirow[b]{2}{*}{ Variable } & \multicolumn{2}{|c|}{ Group $1\left(<60 \mathrm{~mL} / \mathrm{m}^{2} ; \mathrm{n}=148\right)$} & \multicolumn{2}{|c|}{ Group $2\left(60-90 \mathrm{~mL} / \mathrm{m}^{2} ; n=203\right)$} & \multicolumn{2}{|c|}{ Group $3\left(>90 \mathrm{~mL} / \mathrm{m}^{2} ; \mathbf{n}=204\right)$} \\
\hline & $\begin{array}{c}\text { CABG } \\
(n=82)\end{array}$ & $\begin{array}{c}\text { CABG }+ \text { SVR } \\
(\mathbf{n}=\mathbf{6 6}) \\
\end{array}$ & $\begin{array}{c}\text { CABG } \\
(n=114)\end{array}$ & $\begin{array}{c}\text { CABG }+ \text { SVR } \\
(\mathbf{n}=\mathbf{8 9}) \\
\end{array}$ & $\begin{array}{c}\text { CABG } \\
(\mathbf{n}=\mathbf{1 0 0})\end{array}$ & $\begin{array}{c}\text { CABG }+ \text { SVR } \\
(n=104) \\
\end{array}$ \\
\hline \multicolumn{7}{|l|}{ Mean LVESVI } \\
\hline Preoperative & 49 & 48 & 74 & 74 & 117 & 120 \\
\hline Postoperative & 50 & 47 & 72 & 59 & 99 & 88 \\
\hline$P$ value* & .75 & .46 & .45 & $<.0001$ & $<.0001$ & $<.0001$ \\
\hline No reduction in ESVI (\%) & 51 & 41 & 47 & 12 & 27 & 17 \\
\hline$>30 \%$ Reduction in ESVI $(\%)$ & 22 & 26 & 18 & 36 & 26 & 45 \\
\hline \multicolumn{7}{|l|}{ Mean LVESVI } \\
\hline Preoperative & 78 & 76 & 104 & 106 & 151 & 153 \\
\hline Postoperative & 79 & 77 & 105 & 91 & 131 & 121 \\
\hline$P$ value & .51 & .96 & .86 & $<.0001$ & $<.0001$ & $<.0001$ \\
\hline \multicolumn{7}{|l|}{ Mean LVEF } \\
\hline Preoperative & 0.37 & 0.36 & 0.29 & 0.30 & 0.23 & 0.22 \\
\hline Postoperative & 0.39 & 0.40 & 0.33 & 0.36 & 0.27 & 0.28 \\
\hline$P$ value & .18 & .008 & .001 & $<.0001$ & .0002 & $<.0001$ \\
\hline
\end{tabular}

$C A B G$, Coronary artery bypass grafting; $E D V I$, end-diastolic volume index; $E S V I$, end-systolic volume index; $L V$, left ventricular; $L V E F$, left ventricular ejection fraction; $L V E S V I$, left ventricular end-systolic volume index; SVR, surgical ventricular reconstruction. *Paired $t$ test. 
0.22 at baseline to 0.28 at 4 months, $45 \%$ of patients had a greater than $30 \%$ reduction in LVESVI from baseline, and $17 \%$ had no reduction or an increase in LVESVI. Patients receiving $\mathrm{CABG}$ alone also had a significant increase in LVEF (from 0.23 to $0.27 ; P=.0002$ ), $26 \%$ had a greater than $30 \%$ reduction in LVESVI, and $27 \%$ had no change or an increase in ESVI.

The mean change in the end-diastolic volume index from baseline to 4 months in the 555 patients segregated by treatment received was similar to the mean change in LVESVI (Table 2).

\section{Survival According to Baseline LVESVI: Effect of SVR}

Stratification of the 555 patients according to the 3 baseline LVESVI subgroups revealed no statistically significant survival benefit from SVR but suggested that patients with relatively smaller ventricles did better with SVR than those with larger ventricles (Figure E5). When the 148 patients in group 1 with relatively smaller ventricles at baseline (LVESVI $<60 \mathrm{~mL} / \mathrm{m}^{2}$ ) were excluded from the survival analysis, the Kaplan-Meier cumulative risk of death estimate for the remaining 407 patients with an LVESVI of $60 \mathrm{~mL} / \mathrm{m}^{2}$ or more did not show a statistically significant difference in mortality between the 2 treatment groups (HR, 0.96; 95\% CI, 0.63-1.44; log-rank $P=.8253$ ).

\section{Survival According to Postoperative LVESVI: Effect of SVR}

Kaplan-Meier mortality estimates of the 555 patients with paired LVESVI measurements, classified according to the 4-month postoperative LVESVI, are presented in Figure 1. This analysis indicated enhanced survival with CABG plus SVR compared with CABG alone for patients who achieved a 4-month ESVI of $70 \mathrm{~mL} / \mathrm{m}^{2}$ or less and a worse outcome for patients with a greater 4-month LVESVI. The 4-year Kaplan-Meier mortality estimates suggested that the 4-month postoperative LVESVI had little effect on survival in patients undergoing CABG alone. In patients treated with CABG plus SVR, a statistically significant reduction in mortality was achieved in those patients attaining an ESVI of less than $60 \mathrm{~mL} / \mathrm{m}^{2}$ compared with CABG plus SVR patients attaining an ESVI of $60 \mathrm{~mL} / \mathrm{m}^{2}$ or more (HR, 0.33; 95\% CI, 0.17-0.62; log-rank $P=.0004$; Figure 2). This relationship was not significant in patients treated with CABG alone (HR, 0.68; 95\% CI, $0.41-1.15$; log-rank $P=.1519$; Figure E6).

A similar trend was observed regarding the magnitude of decrease in LVESVI after CABG plus SVR, using a threshold of $30 \%$ or more reduction in LVESVI. No statistically significant difference was seen in survival between patients treated with CABG alone versus CABG plus SVR; however, attainment of this threshold reduction appeared to be more important for survival in patients with $\mathrm{CABG}$ plus
SVR $(P=.09)$ than in patients with CABG alone (Figure 3 and Figure E7). Of the 555 patients, 64 receiving CABG alone and 96 receiving CABG plus SVR achieved a $30 \%$ or more reduction in ESVI.

A total of 145 patients had a change from baseline in the LVESVI of $25 \mathrm{~mL} / \mathrm{m}^{2}$ or less and 410 patients had a change from baseline in the LVESVI of more than $25 \mathrm{~mL} / \mathrm{m}^{2}$. There appeared to be little effect from SVR for whether the 4-month LVESVI showed a "small" $\left(\leq 25 \mathrm{~mL} / \mathrm{m}^{2}\right)$ or "large" $(>25$ $\mathrm{mL} / \mathrm{m}^{2}$ ) reduction in LVESVI, regardless of the baseline LVESVI (Figure E5).

\section{DISCUSSION}

The beneficial effects of reverse remodeling reported with medical therapy in patients with ischemic LV dysfunction resulted in the evolution of a surgical procedure to reduce the LV volume and wall tension, with the expectation of a similar benefit. The objective of SVR is to create a smaller left ventricle with a more natural elliptical shape. The CABG plus SVR operation has been shown to reduce the LV volume, increase the LVEF, and improve clinical symptoms. ${ }^{6,11-13}$ On the basis of registry data and a small, nonrandomized, case-control study, it was proposed that SVR performed with CABG would provide patient benefit beyond that of CABG alone. ${ }^{13}$ However, CABG plus SVR had not been compared with CABG alone in a randomized clinical trial until STICH. Because the beneficial treatment effects on reverse remodeling are well known to be time dependent in ischemic heart failure, a 4-month point was selected for endpoint analysis in STICH. ${ }^{8}$

Significant limitations to these analyses were present. First, only 924 of the 1000 STICH patients had a measurable baseline ESVI. Second, only 555 patients had paired preand postoperative studies of fair to excellent quality using the same imaging modality. Third, the present analysis evaluated a broad range of baseline LVESVIs $\left(22-231 \mathrm{~mL} / \mathrm{m}^{2}\right.$ ). Fourth, structural and hemodynamic variables related to LV function, such as the sphericity index, conicity index, extent and severity of anterior wall asynergy, diastolic parameters, mitral regurgitation, and the presence of viable myocardium were not evaluated. Finally, factors related to the conduct of surgery such as mitral valve surgery and the use of a patch for SVR were not analyzed.

\section{Change in LVESVI With CABG Plus SVR and CABG Alone}

In STICH, the likelihood of achieving any reduction in LVESVI or a major reduction $(\geq 30 \%)$ from baseline was related to the baseline ESVI for each treatment assignment; patients with the largest ventricles (group 3) were the most likely and those with smallest ventricles (group 1) the least likely. The magnitude of LVESVI reduction was significantly greater with SVR across the entire spectrum of baseline LVESVI. In fact, $42 \%$ of all CABG alone patients had 


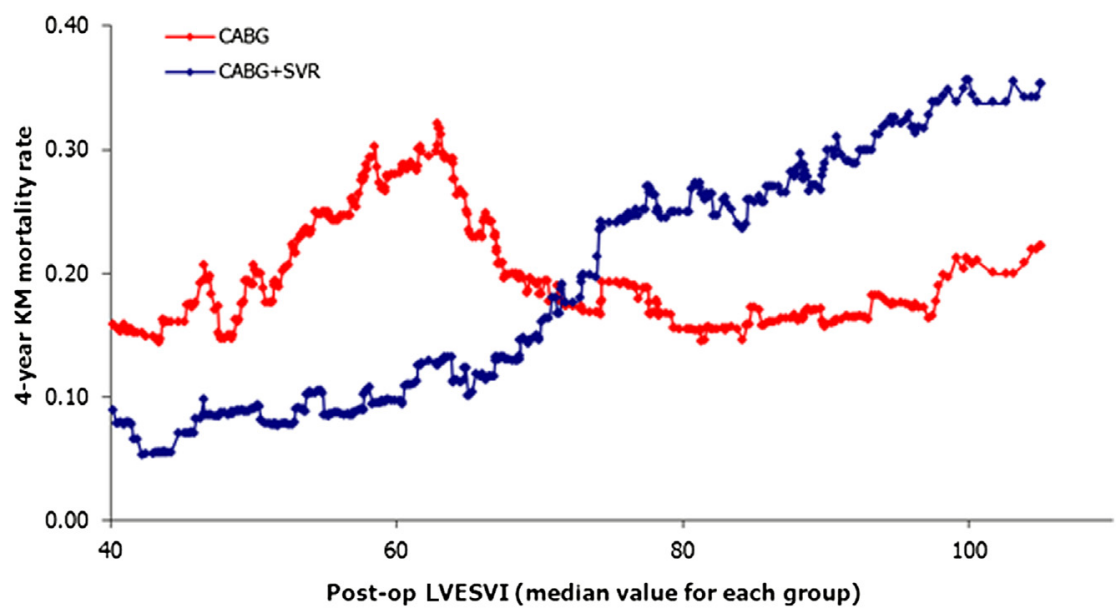

FIGURE 1. Rolling 4-year Kaplan-Meier (KM) estimates by operation received and postoperative (post-op) left ventricular end-systolic volume index (LVESVI) for 555 patients with paired LVESVI data. Total group size, 150; increment, 1. CABG, Coronary artery bypass grafting; SVR, surgical ventricular reconstruction.

no change or an increase in LVESVI at 4 months. However, a number of SVR patients also had no change or an increase in LVESVI at 4 months. It is important to recognize that with either CABG alone or CABG plus SVR, no reduction or an increase in LVESVI at 4 months could be explained by the continued LV remodeling that occurs after operation. It is for this reason that the follow-up point of 4 months in STICH is so critical to understanding the results of SVR. Many published reports, including the nonrandomized, retrospective Reconstructive Endoventricular Surgery Returning Torsion Original Radius Elliptical (RESTORE) group data, assessed patients early after surgery and before hospital discharge, often within 1 week of surgery. Not only is the early postoperative period recognized as a time of ongoing hemodynamic change for patients with heart failure, but also, insufficient time would have elapsed to assess the full effect of the SVR procedure, including additional LV remodeling.

\section{Effect of CABG Alone on LV Remodeling, Function, and Survival: Influence of LVESVI}

Increasing LVESVI has been associated with worse survival in almost all studies in which patients with LV systolic dysfunction have been reported, particularly in patients after myocardial infarction. The STICH data suggest that the beneficial effects of $\mathrm{CABG}$ on reverse $\mathrm{LV}$ remodeling increase as the preoperative LVESVI increases. In STICH, coronary revascularization alone in patients with the largest ventricles (LVESVI $>90 \mathrm{~mL} / \mathrm{m}^{2}$ ) resulted in the greatest mean reduction in LVESVI $\left(\sim 18 \mathrm{~mL} / \mathrm{m}^{2}\right)$ compared with all patients who had undergone $\mathrm{CABG}$ alone. Although these reductions were statistically significant compared with baseline, the clinical relevance of these reductions depends on the baseline LVESVI. The reduction of $18 \mathrm{~mL} / \mathrm{m}^{2}$ in the group $3 \mathrm{CABG}$ alone patients with a baseline mean LVESVI of $117 \mathrm{~mL} / \mathrm{m}^{2}$ would be unlikely to produce clinical benefit.

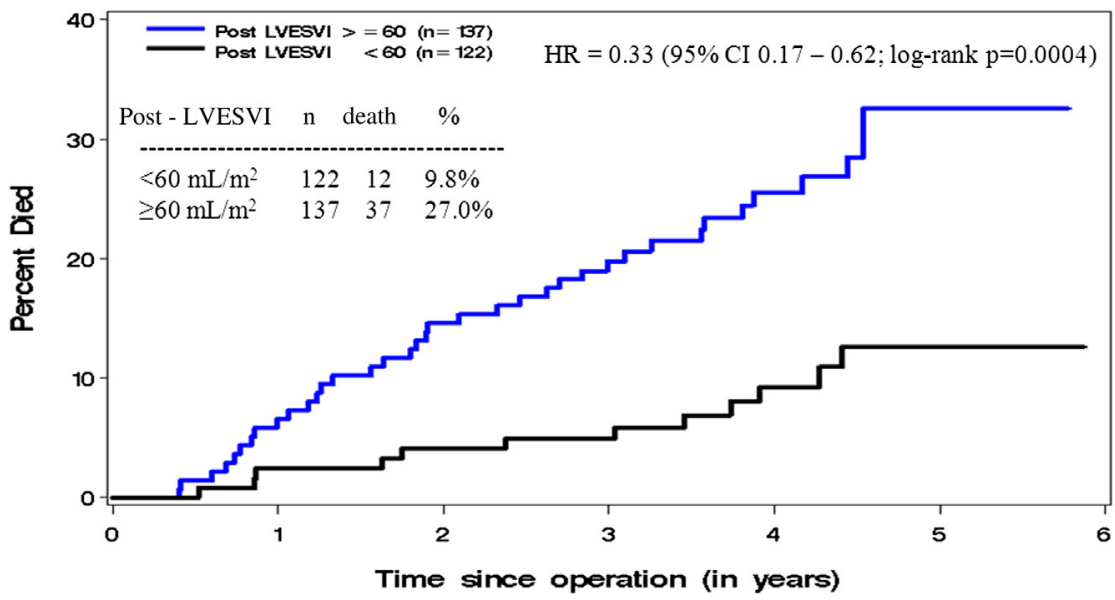

FIGURE 2. Cumulative risk of death: coronary artery bypass grafting plus surgical ventricular reconstruction patients $(\mathrm{n}=259)$ and postoperative left ventricular end-systolic volume index (LVESVI) less than or $\geq 60 \mathrm{~mL} / \mathrm{m}^{2}$. HR, Hazard ratio; $C I$, confidence interval. 


\section{Kaplan-Meier Curves: Cumulative risk of death} CABG + SVR patients with same modality

$(n=259)$

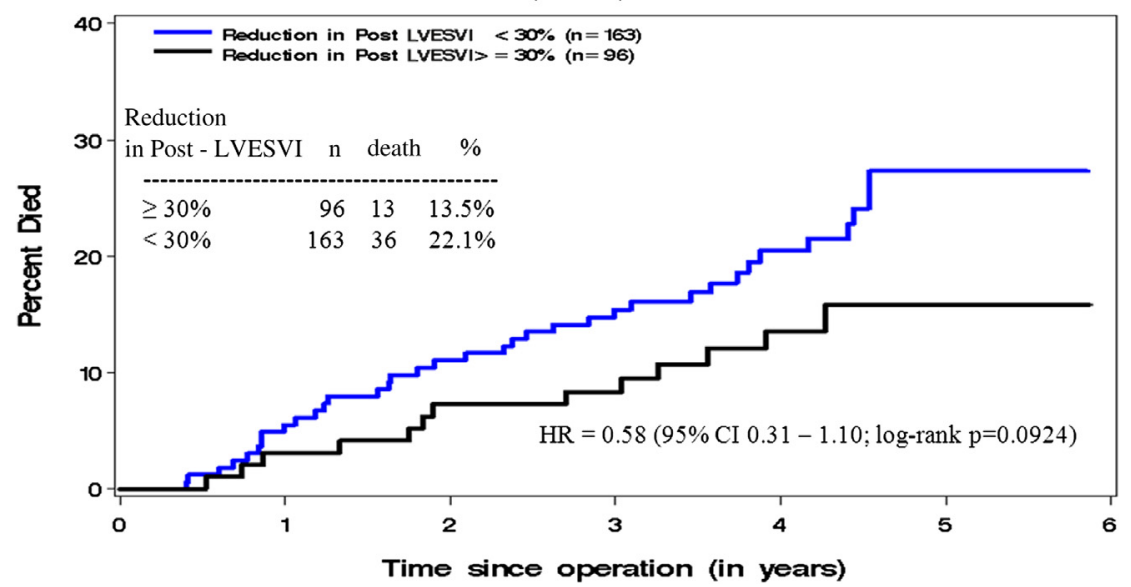

FIGURE 3. Cumulative risk of death: coronary artery bypass grafting $(C A B G)$ plus surgical ventricular reconstruction $(S V R)$ and reduction in postoperative left ventricular end-systolic volume index (LVESVI) less than or $\geq 30 \%$ of baseline LVESVI. $H R$, Hazard ratio; $C I$, confidence interval.

Judging from the reduction in LVESVI seen with CABG alone in the STICH patients with the largest baseline LVESVI one might conclude that viable nonfunctioning myocardium appears to be greater in patients with a larger baseline LVESVI and that this muscle can be recruited, undergo reverse remodeling, and become functional after revascularization. It is not known whether the amount of viable myocardium and the extent of asynergy varied among the 3 LVESVI groups, which could also explain the variability among the 3 groups in the reduction of LVESVI with CABG alone.

\section{Effect of SVR on LV Remodeling, Function, and Survival: Influence of LVESVI}

Di Donato and colleagues ${ }^{5}$ reported that a preoperative LVESVI greater than $94 \mathrm{~mL} / \mathrm{m}^{2}$ was the maximum baseline LVESVI that could result in a less than $60 \mathrm{~mL} / \mathrm{m}^{2}$ LVESVI after surgery. Those data suggest that there might be a point of no return for ventricular remodeling beyond which SVR, despite achieving a volume reduction, is unlikely to reduce the LVESVI sufficiently to provide benefit. This observation is consistent with recent evidence from the cardiac resynchronization therapy data, in which Carluccio and colleagues ${ }^{14}$ showed that extensive LV remodeling/dilatation at baseline was associated with poor functional improvement and more frequent cardiac events at follow-up.

The results of STICH support a lack of benefit of SVR compared with CABG alone when SVR was performed in patients with the largest ventricles (baseline LVESVI $>90 \mathrm{~mL} / \mathrm{m}^{2}$ ), despite obtaining significant reductions in LVESVI. Patients with the largest ventricles (group 3) who underwent CABG plus SVR had an average baseline LVESVI of $120 \mathrm{~mL} / \mathrm{m}^{2}$, which decreased to an average
LVESVI of $88 \mathrm{~mL} / \mathrm{m}^{2}$. This represents a large reduction (27\% reduction in the mean value) and a significantly greater reduction than that achieved with CABG alone, without a survival benefit. Despite a large percentage of LVESVI reduction, it is unknown whether the absence of a survival benefit is attributable to the absolute value of the LVESVI reduction. Also, it is unknown whether in patients with the largest ventricles, surgeons were less vigorous with volume reduction for reasons that included a concern for diastolic performance.

Patients with a baseline LVESVI less than $60 \mathrm{~mL} / \mathrm{m}^{2}$ have been thought to be suboptimal candidates for SVR owing to the more limited capacity to reduce LVESVI. An LVESVI of $60 \mathrm{~mL} / \mathrm{m}^{2}$ is not a small ventricle, because the normal ESVI is approximately $25 \mathrm{~mL} / \mathrm{m}^{2}$. STICH has been criticized for having included such patients. ${ }^{2,4}$ SVR had less effect on LVESVI in these patients, with LVESVI decreasing $30 \%$ or more in $26 \%$ of patients after SVR and $41 \%$ having no reduction or an increase in LVESVI. Despite this relative lack of reduction in LVESVI there was no signal of harm and, if anything, a trend toward improved outcomes with SVR in these patients (Figure E5). ${ }^{7}$ Moreover, excluding patients with a baseline ESVI less than $60 \mathrm{~mL} / \mathrm{m}^{2}$ from the survival analysis had no effect on treatment outcome.

Di Donato and colleagues ${ }^{5,6}$ suggested that 1 of the goals of SVR is reconstruction of the ventricle to an LVESVI less than $60 \mathrm{~mL} / \mathrm{m}^{2}$. The results of STICH support this observation and suggest that the postoperative cutoff for benefit could be greater and closer to $70 \mathrm{~mL} / \mathrm{m}^{2}$ (Figure 1). The 4-year Kaplan-Meier mortality estimates indicated enhanced survival with CABG plus SVR for patients who achieved an LVESVI of $70 \mathrm{~mL} / \mathrm{m}^{2}$ or less and 
a worse outcome for patients with a greater 4-month LVESVI. The 4-month postoperative LVESVI had little effect on survival in patients with CABG alone.

Why the survival curves in Figure 1 cross at close to $70 \mathrm{~mL} / \mathrm{m}^{2}$ is speculative, but it might be that in some patients, the left ventricle continues to enlarge between the early postoperative period when the RESTORE group performed their follow-up echocardiograms and the 4-month period when postoperative imaging was performed in STICH. It is uncertain why attaining a smaller postoperative LVESVI would provide a survival advantage with SVR and not with CABG. In contrast, patients with a larger postoperative LVESVI after SVR did worse than patients with a similar LVESVI after CABG alone (Figure 1).

No difference was seen in survival between $\mathrm{CABG}$ alone and CABG plus SVR according to whether the LVESVI was decreased by $25 \mathrm{~mL} / \mathrm{m}^{2}$ or more. However, a $30 \%$ or more reduction in LVESVI might have a more important effect on survival in patients with CABG plus SVR than in patients with $\mathrm{CABG}$ alone (Figure 3 and Figure E7). In patients with a baseline LVESVI greater than $90 \mathrm{~mL} / \mathrm{m}^{2}$, the percentage of reduction in the average LVESVI compared with baseline with SVR was $27 \%$. In addition, $45 \%$ of patients with a baseline LVESVI greater than $90 \mathrm{~mL} / \mathrm{m}^{2}$ achieved a reduction of $30 \%$ or more. We do not know whether the surgeons were reluctant to more aggressively reduce the LVESVI in these group 3 patients, thereby leaving the postoperative LVESVI at a level insufficient to achieve a survival benefit. An alternative is that the surgeons were sufficiently aggressive and did achieve greater early postoperative reductions only to have reverse remodeling undermine the greater reductions by the 4-month endpoint analysis. The STICH data cannot reveal whether greater LVESVI reductions were achieved at 1 week after surgery only to enlarge with reverse remodeling at the 4month observation point.

Several major observations are evident from the present post hoc STICH subgroup analysis. First, a postoperative LVESVI of $70 \mathrm{~mL} / \mathrm{m}^{2}$ or less after CABG plus SVR resulted in improved survival compared with $\mathrm{CABG}$ alone, and the contrary was true with a postoperative LVESVI of $70 \mathrm{~mL} /$ $\mathrm{m}^{2}$ or more. Second, in patients treated with CABG plus SVR, those who achieved a postoperative LVESVI less than $60 \mathrm{~mL} / \mathrm{m}^{2}$ manifested statistically significant improved survival compared with those CABG plus SVR and a postoperative LVESVI of $60 \mathrm{~mL} / \mathrm{m}^{2}$ or more. This was not true for those treated with $\mathrm{CABG}$ alone. Third, compared with CABG alone, survival after SVR was not influenced by whether SVR achieved a large or small volume reduction ( $<25$ or $\geq 25 \mathrm{~mL} / \mathrm{m}^{2}$ ). Finally, in the limited number of patients achieving a postoperative LVESVI reduction of $30 \%$ or more compared with baseline, CABG plus SVR did not provide a statistically significant survival benefit compared with CABG alone.

\section{CONCLUSIONS}

SVR continues to have a role in the treatment of patients with ischemic cardiomyopathy. In patients for whom SVR is planned, survival will be improved in those achieving a postoperative LVESVI of $70 \mathrm{~mL} / \mathrm{m}^{2}$ or less. The very large, extensively remodeled, left ventricle at baseline might limit the ability of SVR to achieve a sufficient reduction in LVESVI and, therefore, to derive a clinical benefit.

\section{References}

1. Jones RH, Velazquez EJ, Michler RE, Sopko G, Oh JK, O'Connor CM, et al. Coronary bypass surgery with or without surgical ventricular reconstruction. $N$ Engl J Med. 2009;360:1705-17.

2. Buckberg GD, Anthanasuleas CL, Wechsler AS, Beyersdorf F, Conte JV, Strobeck JE. The STICH trial unravelled. Eur J Heart Fail. 2010;12:1024-7.

3. Rouleau JL, Michler RE, Velazquez EJ, Oh JK, O'Connor CM, DesvigneNickens P, et al. The STICH trial: evidence-based conclusions. Eur J Heart Fail. 2010;12:1028-30

4. Conte J. An indictment of the STICH trial: "true, true, and unrelated." J Heart Lung Transplant. 2010;29:491-6.

5. Di Donato M, Castelvecchio S, Menicanti L. End-systolic volume following surgical ventricular reconstruction impacts survival in patients with ischaemic dilated cardiomyopathy. Eur J Heart Fail. 2010;12:375-81.

6. Di Donato M, Tosa A, Maioli M, Sabatier M, Stanley AW Jr, Dor V. Intermediate survival and predictors of death after surgical ventricular restoration. Semin Thorac Cardiovasc Surg. 2001;13:468-75.

7. Oh JK, Velazquez EJ, Menicanti L, Pohost GM, Bonow RO, Lin G, et al. Influence of baseline left ventricular function on the clinical outcome of surgical ventricular reconstruction in patients with ischemic cardiomyopathy. Eur Heart $J$ Epub 2012 May 14.

8. Velazquez EJ, Lee KL, O'Connor CM, Oh JK, Bonow RO, Pohost GM, et al. The rationale and design of the Surgical Treatment for Ischemic Heart Failure (STICH) trial. J Thorac Cardiovasc Surg. 2007;134:1540-7.

9. Kaplan EL, Meier P. Nonparametric estimation from incomplete observations. J Am Stat Assoc. 1958;53:457-81.

10. Cox DR. Regression models and life-tables (with discussion). J R Stat Soc Series B Stat Methodol. 1972;34:187-220.

11. Menicanti L, Castelvecchio S, Ranucci M, Frigiola A, Santambrogio C, de Vincentiis C, et al. Surgical therapy for ischemic heart failure: single-center experience with surgical anterior ventricular restoration. J Thorac Cardiovasc Surg 2007; 134:433-41.

12. Athanasuleas CL, Buckberg GD, Stanley AW, Siler W, Dor V, Di Donato M, et al Surgical ventricular restoration in the treatment of congestive heart failure due to post-infarction ventricular dilation. J Am Coll Cardiol. 2004;44:1439-45.

13. Prucz RB, Weiss ES, Patel ND, Nwakanna LU, Baumgartner WA, Conte JV. Coronary artery bypass grafting with or without surgical ventricular restoration: a comparison. Ann Thorac Surg. 2008;86:806-14.

14. Carluccio E, Biagioli P, Alunni G, Murrone A, Pantano P, Biscottini E, et al Presence of extensive LV remodeling limits the benefits of CRT in patients with intraventricular dyssynchrony. JACC Cardiovasc Imaging. 2011;4: 1067-76. 


\begin{tabular}{|c|c|c|}
\hline $\begin{array}{l}\text { Operated Patients } \\
\qquad N=979\end{array}$ & 86 died before 4 months & $86(9 \%)$ of operated patients \\
\hline \multirow{2}{*}{$\begin{array}{l}\text { Patients eligible for } \\
\text { paired study analysis } \\
\qquad N=893\end{array}$} & 16 NO baseline study & \multirow{2}{*}{$\begin{array}{l}13 \text { Specific reasons provided } \\
\text { for missing study } \\
3 \text { Unexplained }\end{array}$} \\
\hline & sent to core lab & \\
\hline \multirow{2}{*}{$\begin{array}{l}\text { Patients with baseline } \\
\text { studies sent to core lab } \\
\qquad N=877\end{array}$} & 107 NO 4-month study & \multirow{2}{*}{$\begin{array}{l}64 \text { Telephone follow-up only } \\
22 \text { Technical problem } \\
21 \text { Unexplained }\end{array}$} \\
\hline & sent to core lab & \\
\hline \multirow{2}{*}{$\begin{array}{l}\text { Patients with paired } \\
\text { baseline and } 4 \text {-month } \\
\text { studies, } N=770\end{array}$} & 175 patients without & \multirow{2}{*}{$\begin{array}{l}15 \text { Pts with CMR assessment } \\
14 \text { Pts with SPECT assessment } \\
146 \text { Pts with ECHO assessment }\end{array}$} \\
\hline & $\begin{array}{l}\text { both paired studies of } \\
\text { fair to excellent quality }\end{array}$ & \\
\hline \multirow{2}{*}{$\begin{array}{l}\text { Patients with paired } \\
\text { studies, } N=595\end{array}$} & 40 patients excluded & \multirow{3}{*}{$\begin{array}{l}18 \text { pts with baseline CMR } \\
26 \text { pts with baseline ECHO } \\
6 \text { pts with baseline RN } \\
\text { (10 pts with multiple post op) }\end{array}$} \\
\hline & \multirow{2}{*}{$\begin{array}{l}\text { Paired studies of } \\
\text { different modality }\end{array}$} & \\
\hline $\begin{array}{l}\text { Patients with same } \\
\text { modality, } N=555\end{array}$ & & \\
\hline
\end{tabular}

\section{Observational cohort defined by ESVI taken from a randomized population}

FIGURE E1. Paired left ventricular studies before and after operation in 979 surgical ventricular reconstruction hypothesis patients. $C M R$, Cardiac magnetic resonance; core lab, Core Laboratories; ECHO, echocardiography; ESVI, end-systolic volume index; post-op, postoperative; $R N$, radionuclide; SPECT, single photon emission computed tomography.

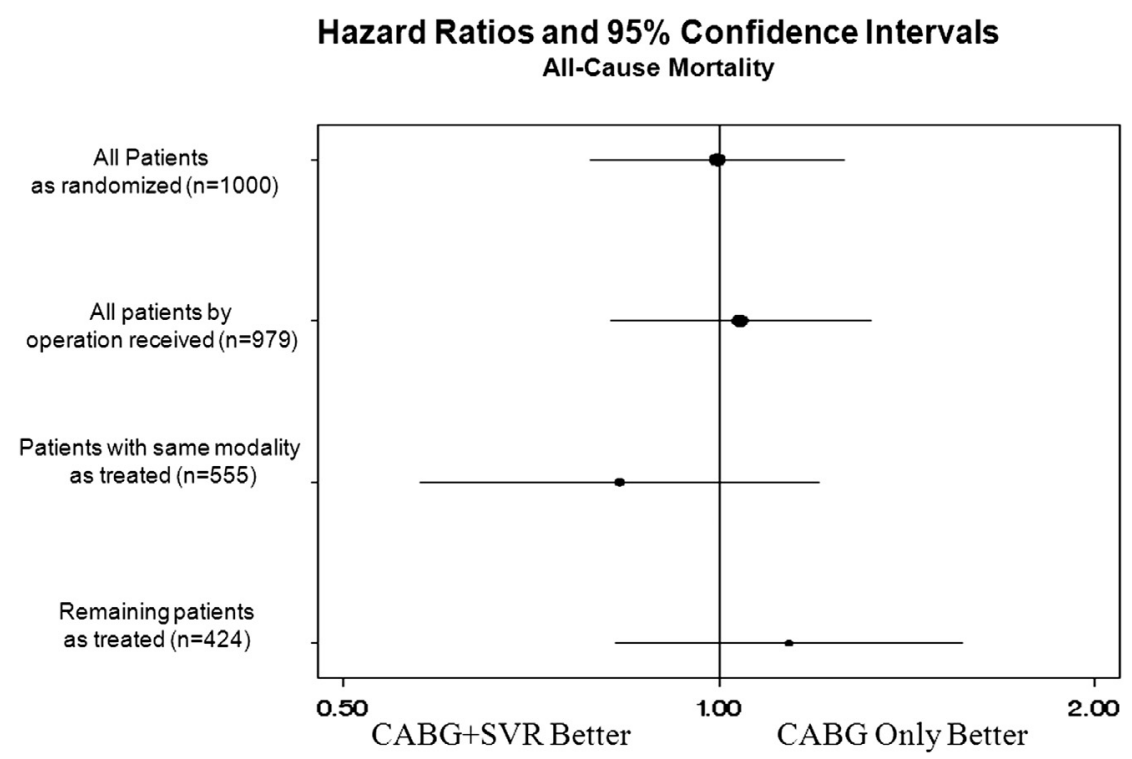

FIGURE E2. All-cause mortality by treatment received in Surgical Treatment for Ischemic Heart Failure. CABG, Coronary artery bypass grafting; SVR, surgical ventricular reconstruction. 


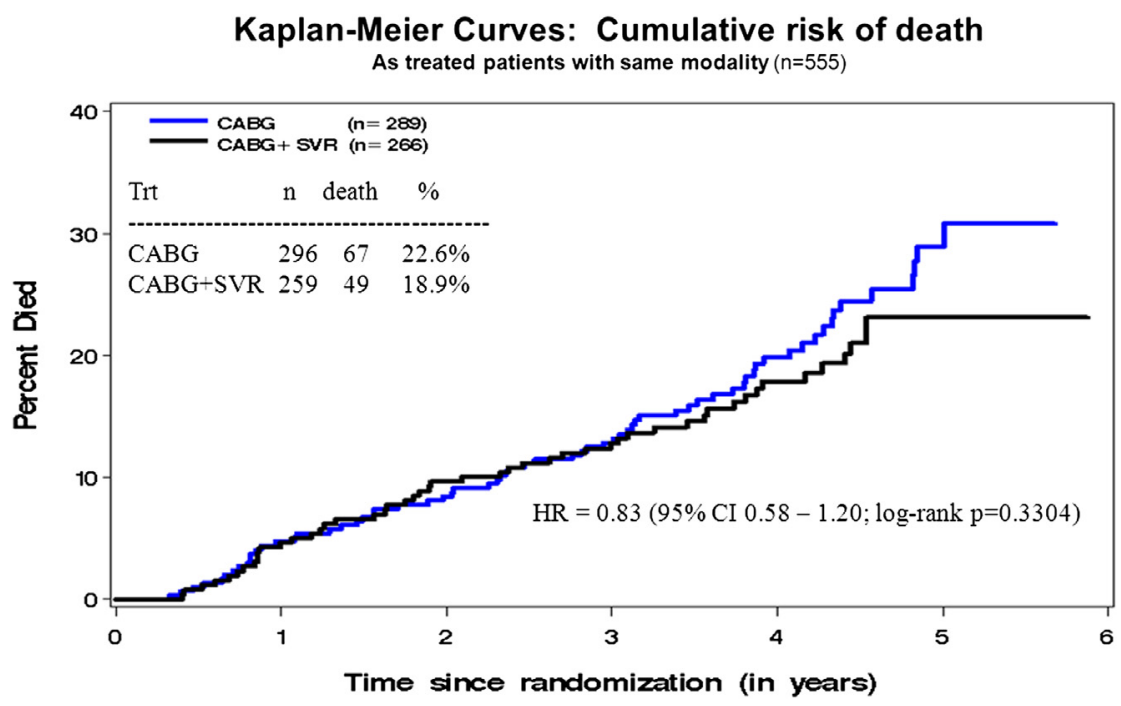

FIGURE E3. Cumulative risk of death: 555 as-treated patients with same (paired) baseline and 4-month imaging modality. $C A B G$, Coronary artery bypass grafting; $C I$, confidence interval; $H R$, hazard ratio; $S V R$, surgical vascular reconstruction. 
Preoperative to Postoperative Change in LVESVI by Operation Received 148 Patients with Baseline LVESVI $<60 \mathrm{~mL} / \mathrm{m}^{2}$

Group 1
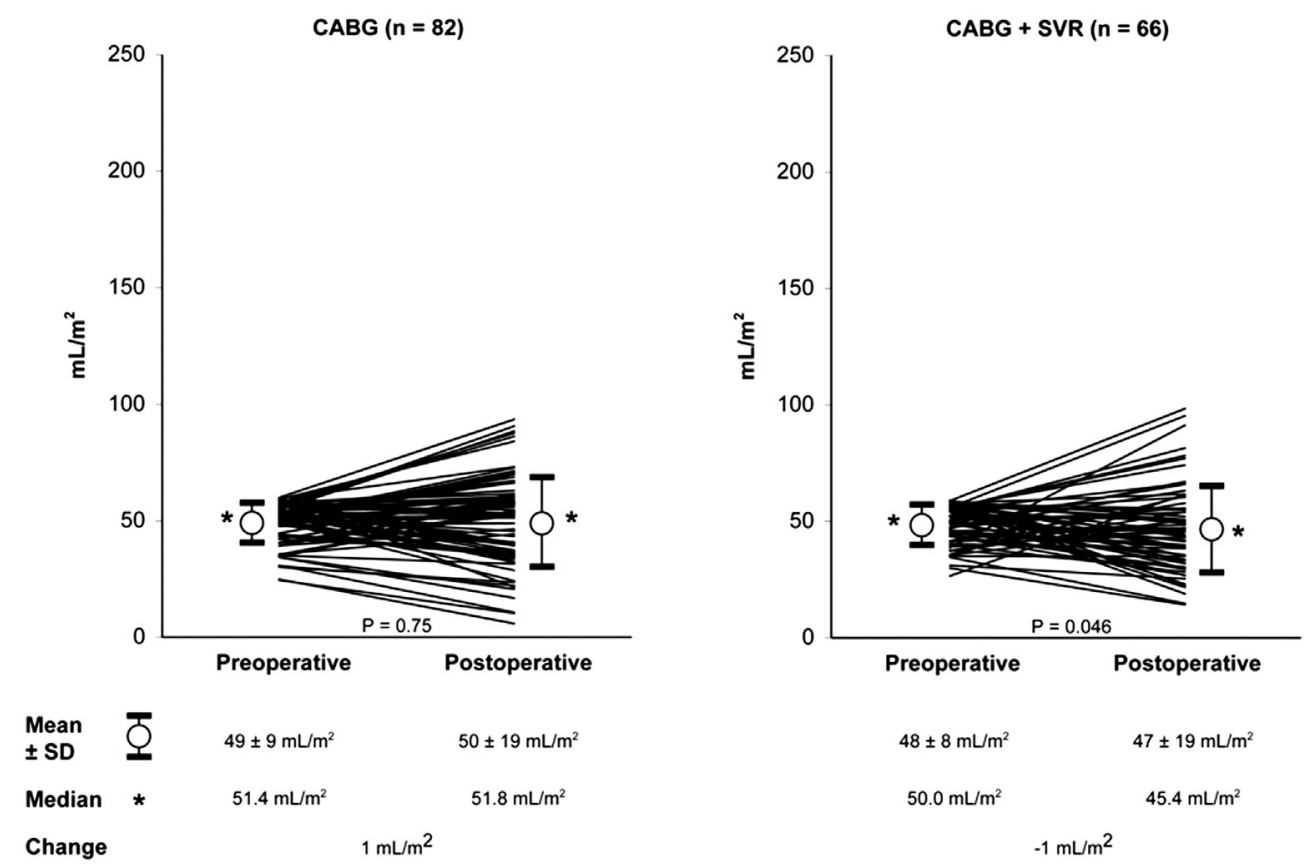

A

Preoperative to Postoperative Change in LVESVI by Operation Received 203 Patients with Baseline LVESVI 60-90 $\mathrm{mL} / \mathrm{m}^{2}$

Group 2
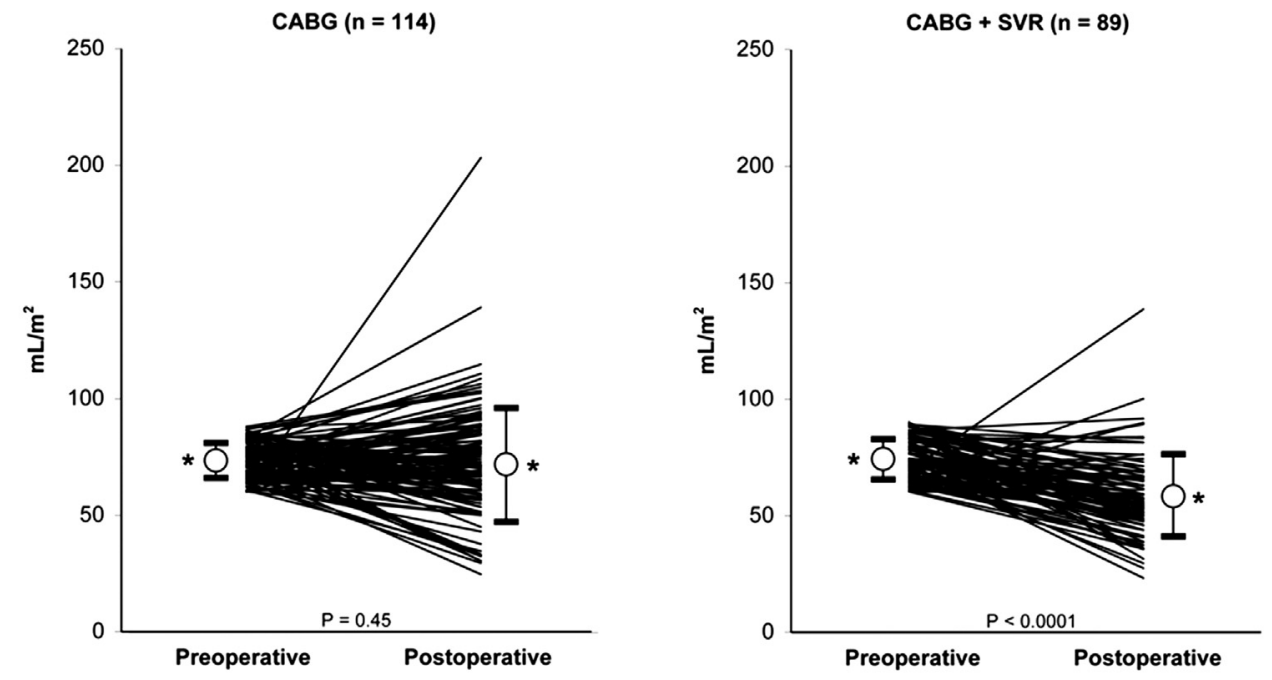

$\begin{array}{llll}\begin{array}{l}\text { Mean } \\ \text { ISD }\end{array} & 74 \pm 8 \mathrm{~mL} / \mathrm{m}^{2} & 72 \pm 24 \mathrm{~mL} / \mathrm{m}^{2} \\ \text { Median } & & 73.7 \mathrm{~mL} / \mathrm{m}^{2} & 70.8 \mathrm{~mL} / \mathrm{m}^{2} \\ \text { Change } & & -2 \mathrm{~mL} / \mathrm{m}^{2} & \end{array}$

$$
\begin{aligned}
& 74 \pm 9 \mathrm{~mL} / \mathrm{m}^{2} \quad 59 \pm 18 \mathrm{~mL} / \mathrm{m}^{2} \\
& 73.3 \mathrm{~mL} / \mathrm{m}^{2} \quad 57.0 \mathrm{~mL} / \mathrm{m}^{2} \\
& -15 \mathrm{~mL} / \mathrm{m}^{2}
\end{aligned}
$$

\section{B}

FIGURE E4. Preoperative to postoperative change in left ventricular end-systolic volume index (LVESVI) by operation received for (A) patients with baseline LVESVI less than $60 \mathrm{~mL} / \mathrm{m}^{2}$, (B) patients with baseline LVESVI $60-90 \mathrm{~mL} / \mathrm{m}^{2}$, and (C) patients with baseline LVESVI greater than $90 \mathrm{~mL} / \mathrm{m}^{2}$. $C A B G$, Coronary artery bypass grafting; $S V R$, surgical vascular reconstruction; $S D$, standard deviation. 


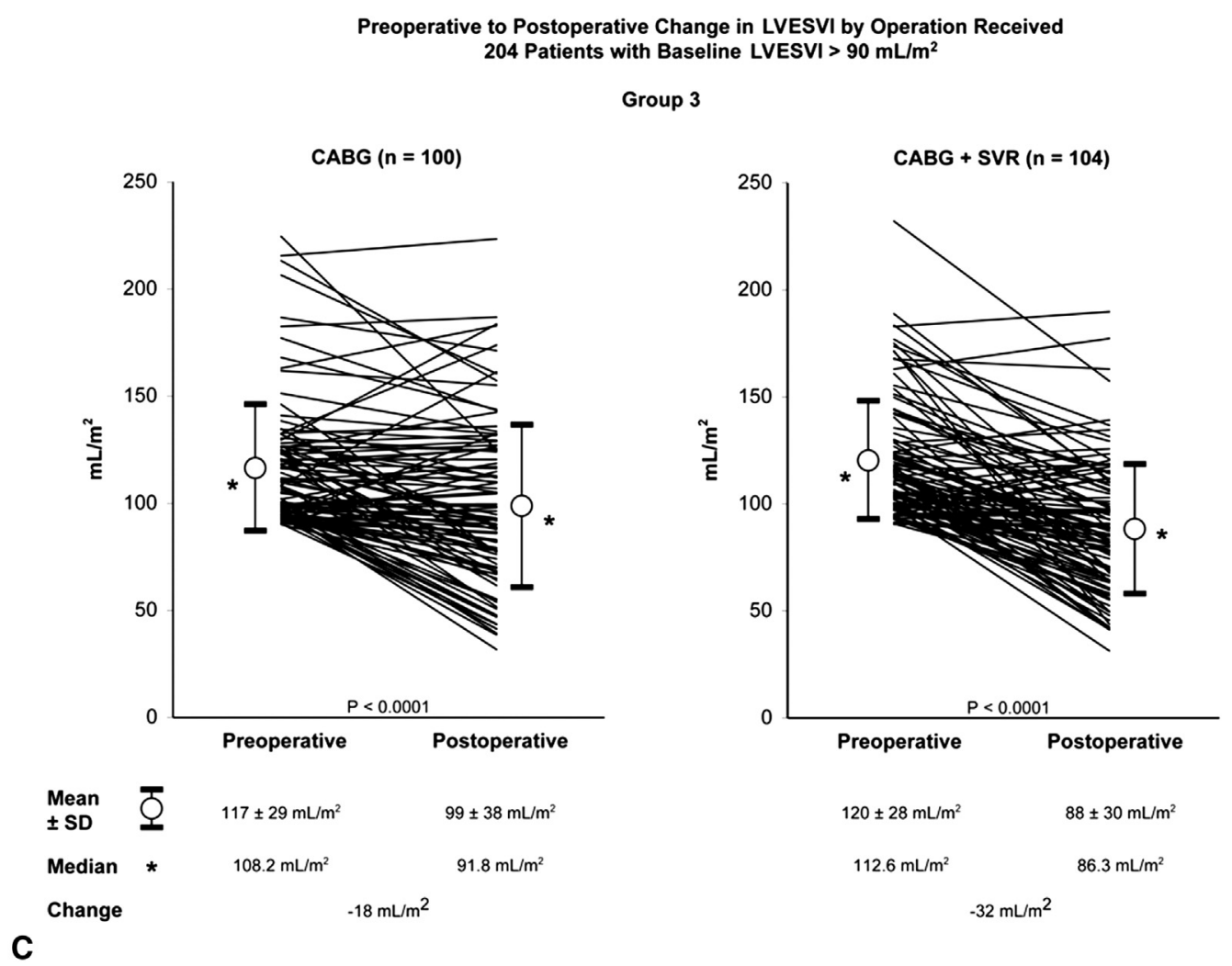

FIGURE E4. (Continued)

Hazard Ratios and $95 \%$ Confidence Intervals All-Cause Mortality

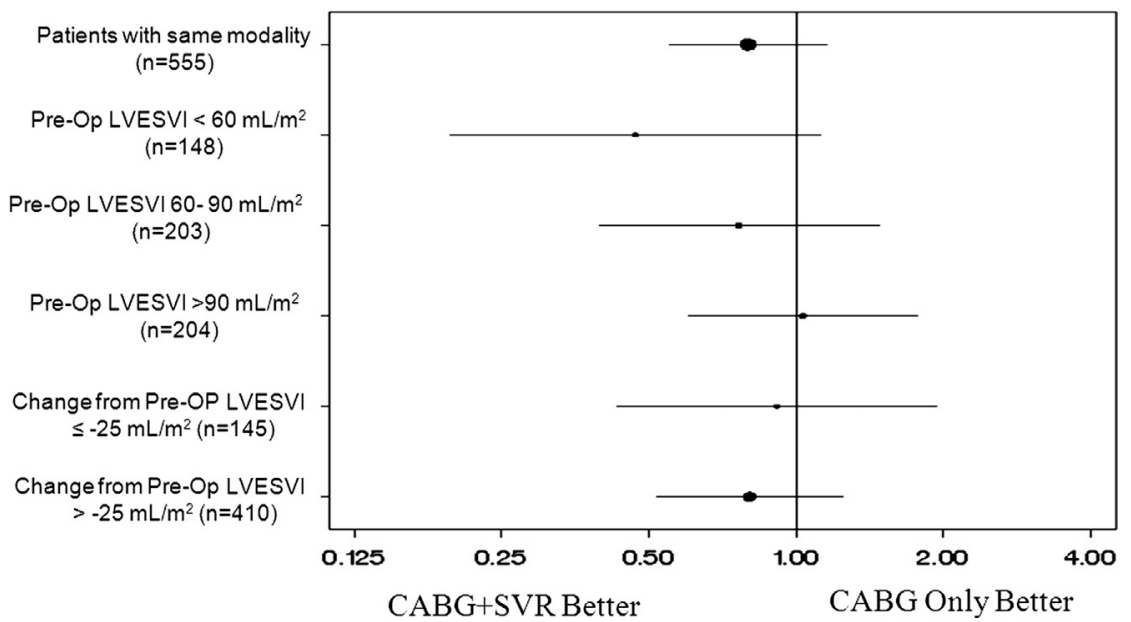

FIGURE E5. All-cause mortality by left ventricular end-systolic volume index (LVESVI) group and change from preoperative (Pre-Op) LVESVI. CABG, Coronary artery bypass grafting; SVR, surgical vascular reconstruction. 


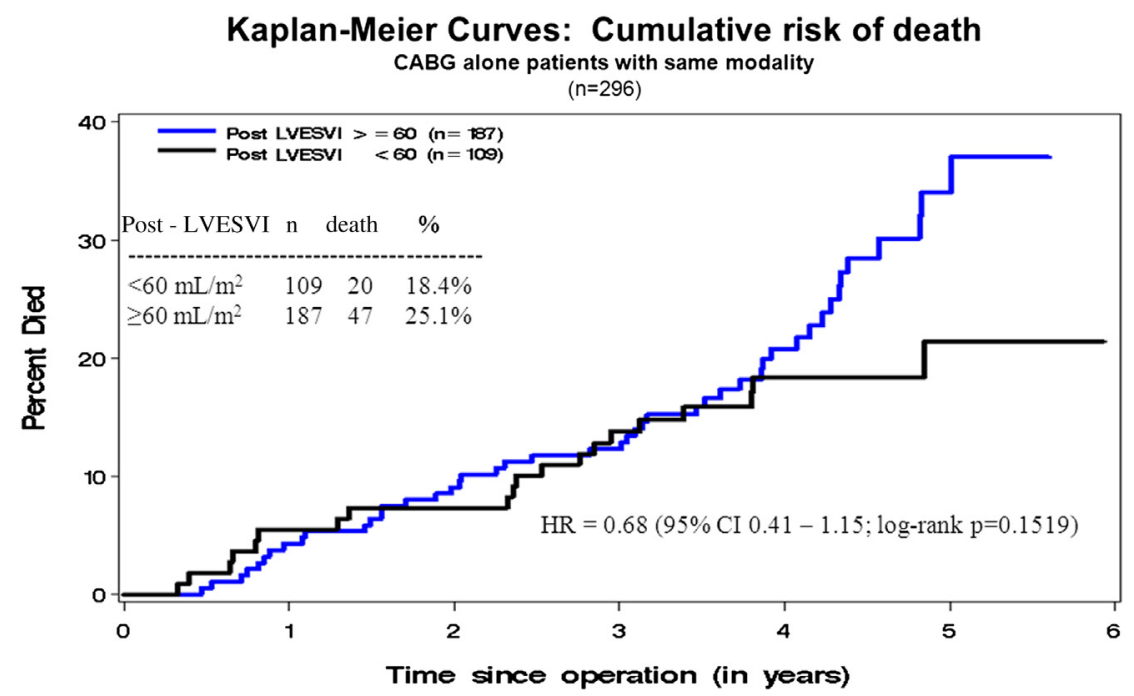

FIGURE E6. Cumulative risk of death for coronary artery bypass grafting (CABG) alone patients and postoperative (Post) left ventricular end-systolic volume index (LVESVI) less than or $60 \mathrm{~mL} / \mathrm{m}^{2}$ or more. $C I$, Confidence interval; $H R$, hazard ratio.

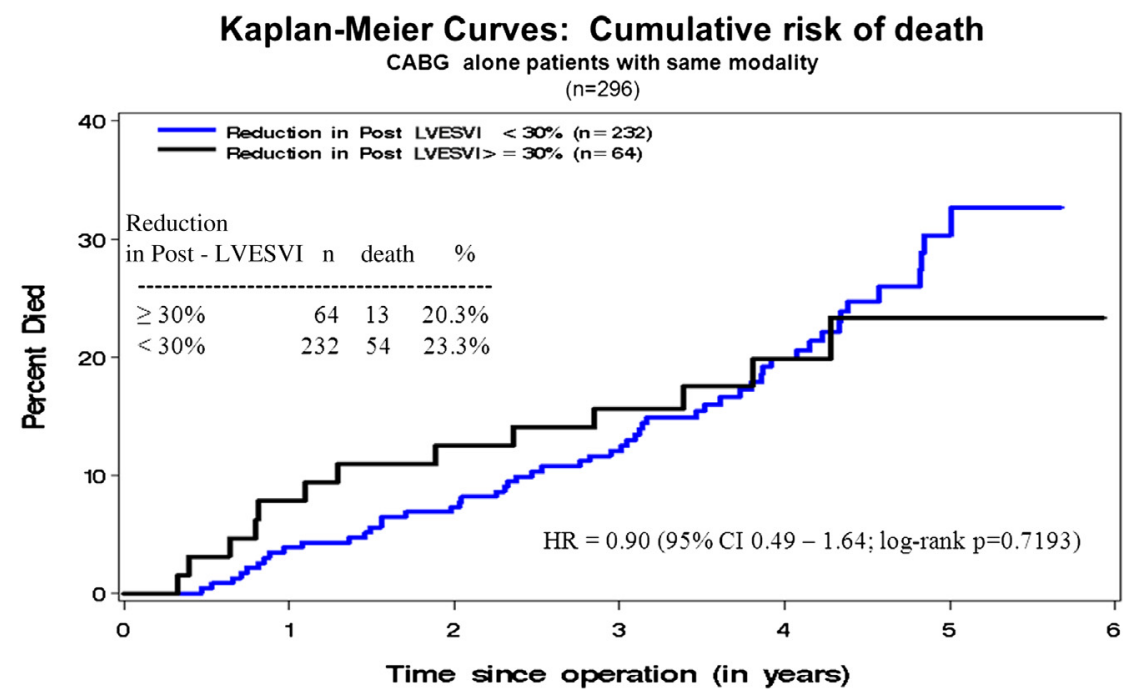

FIGURE E7. Cumulative risk of death for coronary artery bypass grafting $(C A B G)$ alone patients and reduction in postoperative (Post) left ventricular end-systolic volume index (LVESVI) less than or $30 \%$ or more of baseline LVESVI. CI, Confidence interval; HR, hazard ratio. 
TABLE E1. Characteristics of patients with paired imaging studies by treatment assignment

\begin{tabular}{|c|c|c|c|c|c|c|}
\hline \multirow[b]{2}{*}{ Variable } & \multicolumn{3}{|c|}{ CABG alone $(n=296)$} & \multicolumn{3}{|c|}{$\operatorname{CABG}+\operatorname{SVR}(n=259)$} \\
\hline & $\begin{array}{c}\mathrm{ESVI}<60 \\
\mathrm{~mL} / \mathrm{m}^{2}\end{array}$ & $\begin{array}{c}\text { ESVI 60-90 } \\
\mathrm{mL} / \mathrm{m}^{2}\end{array}$ & $\begin{array}{c}\text { ESVI }>90 \\
\mathrm{~mL} / \mathrm{m}^{2}\end{array}$ & $\begin{array}{c}\mathrm{ESVI}<60 \\
\mathrm{~mL} / \mathrm{m}^{2}\end{array}$ & $\begin{array}{c}\text { ESVI 60-90 } \\
\mathrm{mL} / \mathrm{m}^{2}\end{array}$ & $\begin{array}{c}\mathrm{ESVI}>90 \\
\mathrm{~mL} / \mathrm{m}^{2}\end{array}$ \\
\hline Patients (n) & 82 & 114 & 100 & 66 & 89 & 104 \\
\hline Age (y) & $63.1 \pm 10.5$ & $61.8 \pm 8.8$ & $60.0 \pm 9.2$ & $61.9 \pm 9.9$ & $62.0 \pm 10.6$ & $59.8 \pm 8.8$ \\
\hline Female gender $(\%)$ & 26 & 8 & 10 & 14 & 13 & 12 \\
\hline Previous MI (\%) & 89 & 86 & 79 & 80 & 93 & 88 \\
\hline Hypertension $(\%)$ & 52 & 58 & 47 & 64 & 61 & 44 \\
\hline Diabetes $(\%)$ & 38 & 30 & 32 & 32 & 29 & 28 \\
\hline LVEF & $0.37 \pm 0.08$ & $0.29 \pm 0.07$ & $0.23 \pm 0.07$ & $0.36 \pm 0.09$ & $0.30 \pm 0.06$ & $0.22 \pm 0.06$ \\
\hline Angina class III or IV $(\%)$ & 52 & 50 & 43 & 56 & 43 & 50 \\
\hline $\begin{array}{l}\text { NYHA functional class III } \\
\text { or IV }(\%)\end{array}$ & 61 & 63 & 66 & 53 & 64 & 74 \\
\hline Triple vessel disease $(\%)$ & 73 & 68 & 63 & 73 & 57 & 58 \\
\hline Average no. of grafts & 3.2 & 3.3 & 3.2 & 3.3 & 2.9 & 2.8 \\
\hline MR $3+$ or $4+(\%)$ & 11 & 17 & 29 & 2 & 19 & 23 \\
\hline
\end{tabular}

Data presented as mean \pm standard deviation, unless otherwise noted. $C A B G$, Coronary artery bypass grafting; $E S V I$, end-systolic volume index; $L V E F$, left ventricular ejection fraction; $M I$, myocardial infarction; $M R$, mitral regurgitation; NYHA, New York Heart Association; SVR, surgical ventricular reconstruction. 